\title{
Finite Element Analysis of Hydraulic Actuator by using CAE tools
}

\author{
Manisha. Anil. Gurwani \\ Student of Mechanical engineering \\ Babasaheb Naik College of Engineering \\ Pusad, Maharashtra
}

\author{
Prof. V. V. Dongaonkar \\ Associate Professor \\ Dept. Of Mechanical engineering \\ Babasaheb Naik College of Engineering \\ Pusad, Maharashtra
}

\begin{abstract}
A hydraulic system is a fluid power system that is commonly used in industries due to its ability to sustain high pressure .So, here in this paper double acting hydraulic actuator is designed based on the force acting on it and the stroke length .Analysis of different parts of actuators is done by using CAE tools checking for the equivalent stresses and deformation. Two different materials are also used to check proper material to be used.
\end{abstract}

\section{Keywords--- Hydraulic ,actuator, double acting ,analysis}

\section{INTRODUCTION:}

Hydraulic actuators are the end results of Pascal's law. Hydraulic actuator is the device which converts hydraulic energy into mechanical energy it consists of cylinder that transforms the flow of pressurized fluid into a push or pull of piston rod .In double acting actuators the fluid pressure can be exerted from both sides. Hydraulic actuators are rugged and suited for high force applications.

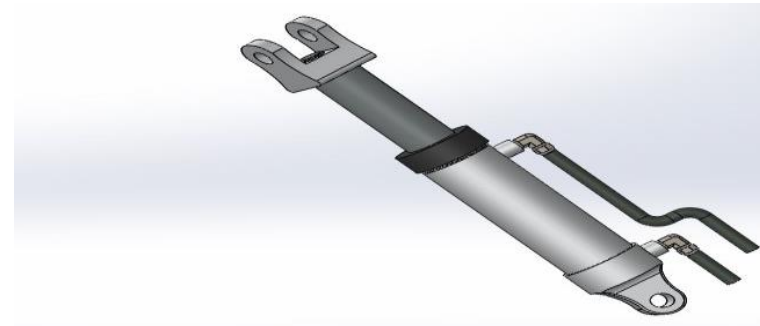

II. METHDOLOGY:

The load of $21832 \mathrm{~N}$ is to be sustained by actuator but if fails suddenly ,so taking into account sudden loading conditions it should be designed for $43664 \mathrm{~N}$ ( $21832 *$ 2).So by using CATIA V5 models are made, and every component is analyzed separately using two different materials that are low carbon steel and E335 steel. Low carbon steel is used as it is lighter in weight with good yield strength, tensile strength, corrosion resistance, ductility whereas E335 steel is practically used in industries as a material. So here we find out which one is better.

\section{DESIGN PROCEDURE}

Let $\mathbf{A}$ be the full area of the piston and $\mathbf{a}$ be the cross sectional area of the piston rod. Since the design is a double acting double ended hydraulic cylinder, pressure is acts on both sides of the rod, hence the area which the pressure is acting on is given by (A-a). The force produced is given in the equation below.
The following assumptions were taken into the consideration of the design of the cylinder, piston, piston rod and seals in the hydraulic cylinder.

Working fluid is mineral oil

Available pressured $\mathrm{Pa}=200 \mathrm{bar}=200 * 10^{5} \mathrm{~Pa}$

Atmospheric pressure $=1.0135 * 10^{5} \mathrm{~Pa}$

Stroke length $=1135 \mathrm{~mm}=1.135 \mathrm{~m}$

Cylinder output force $=43664 \mathrm{~N}$

Factor of safety $=3$

End fixing factor $=\mathrm{K}=0.7$

Properties of materials used

\section{TABLE 1}

\begin{tabular}{|l|l|l|}
\hline \multicolumn{1}{|c|}{ Material } & Low carbon steel & E355 Steel \\
\hline Ultimate tensile stress & $430 \mathrm{MPa}$ & $540-620 \mathrm{MPa}$ \\
\hline Yield tensile stress & $215 \mathrm{MPa}$ & $290-450 \mathrm{MPa}$ \\
\hline Young' Modulus (E) & $210 \mathrm{GPa}$ & $190 \mathrm{GPa}$ \\
\hline
\end{tabular}

A. Design of piston rod

The rod is more likely to fail by buckling under the compressive load. In this case, the rod behaves like a column and is subjected to buckling. Therefore Euler's formula in the equation below for long column can be used to obtain the piston rod diameter

$\mathrm{P}=\pi^{2} \mathrm{EI} / \mathrm{L}^{2} \mathrm{~K}^{2}$

Where: $\mathrm{P}=$ Buckling load $(\mathrm{N})$

$\mathrm{L}=$ the column length $(\mathrm{m})$

$\mathrm{I}=$ Moment of inertia $\left(\mathrm{m}^{4}\right)$

$\mathrm{E}=$ Young's Modulus of Elasticity for the column material $(\mathrm{Pa})$

$\mathrm{K}=$ the end fixing factor $=0.7$

$\mathrm{E}=$ Young's modulus of the material used in this design calculation is $120 \mathrm{GPa}$

$\mathrm{P}=$ cylinder force $*$ factor of safety $=43664 * 3=$ $130992 \mathrm{~N}$

$$
\begin{aligned}
& 130992=\left(\pi^{2 *} 210^{*} 10^{9 *} \mathrm{I}\right) /\left(1.135^{2 *} 0.7^{2}\right) \\
& \mathrm{I}=39.894 * 10^{-9} \mathrm{~m}^{4} \\
& \Pi * \mathrm{~d}^{4} / 4=39.894 * 10^{-9} \\
& \mathrm{~d}=15 \mathrm{~mm}
\end{aligned}
$$

from Baym Hydraulics Corporation catalog of metric rod wipers and piston seals the nearest standard rod seal diameter is $20 \mathrm{~mm}$.

\section{B. Design of the piston}

$$
\begin{aligned}
& \mathrm{A}-\mathrm{a}=\pi\left(\mathrm{D}^{4}-\mathrm{d}^{4}\right) / 4 \\
& 200 * 10^{5}=(43664 * 384) /\left(\pi\left(\mathrm{D}^{2}-0.02^{2}\right)\right. \\
& \mathrm{D}=0.0934 \mathrm{~m}=93.48 \mathrm{~mm}
\end{aligned}
$$

from Baym Hydraulics Corporation catalog of metric rod wipers and piston seals, the nearest standard rod seal diameter is $\mathbf{1 0 0 m m}$ 
2 .length of piston $=\mathrm{D}$ to $1.5 \mathrm{D}=100 \mathrm{~mm}$

3. Thickness of piston head

$\mathrm{t} 1=0.43 \mathrm{D}(\mathrm{P} / \sigma)^{1 / 2}$

$=0.43 * 100 *\left(\left(200 * 10^{5}\right) /\left(55^{*} 10^{6}\right)\right)^{1 / 2}$

$=25.92=26 \mathrm{~mm}$

4 .Radial thickness

$\mathrm{tr}=\mathrm{D}(3 \mathrm{P} / \sigma)^{1 / 2}$

$=0.1\left((3 * 0.03090 /(430 / 3))^{1 / 2}\right.$

$=2.5 \mathrm{~mm}$

C. Design of the cylinder

Let $\mathrm{OD}=$ outside diameter of the cylinder.

The maximum working stress $(\sigma \mathrm{m})$ is given as

$\sigma \mathrm{m}=$ Tensile stress of material/FOS

$=430 / 3$

$=143.3 * 10^{6} \mathrm{~Pa}$

$\mathrm{OD}^{2}=\mathrm{D}^{2}(\sigma \mathrm{m}+\mathrm{P}) /(\sigma \mathrm{m}-\mathrm{P})$ $=0.1^{2}\left(143.3^{*} 10^{6}+200 * 10^{5}\right) /\left(143.3 * 10^{6}-200 * 10^{5}\right)$

$\mathrm{OD}=115 \mathrm{~mm}$

D. Cylinder Tube thickness

The wall thickness required for the cylinder can be calculated from the formula in equation

$\mathrm{t}=(\mathrm{OD}-\mathrm{d}) / 2=(115-100) / 2=7.5 \mathrm{~mm}$

E. Bursting stress

The bursting stress can be referred to as the amounts of hoop stress and longitudinal (axial) stress that are produced in the wall of the cylinder when subjected to internal and external pressures that may cause the material which the cylinder is made from to fail. This happens if the hoops stress exceeds the tensile strength of the material.

The hoop stress $\left(\sigma_{\mathrm{H}}\right)$ of a cylinder can be determined from the Barlow formula as shown in the equation below.

$\sigma_{\mathrm{H}}=\mathrm{P}\left(\left(\mathrm{d}_{\mathrm{o}}{ }^{2}+\mathrm{d}_{\mathrm{i}}^{2}\right) /\left(\mathrm{d}_{\mathrm{o}}{ }^{2}-\mathrm{d}_{\mathrm{i}}^{2}\right)\right)$

Where,

$\mathrm{p}=$ oil pressure, $200 \mathrm{bar}=200 * 10^{5} \mathrm{~Pa}$

$\mathrm{do}=$ outer diameter of cylinder $=55 \mathrm{~mm}$

$\mathrm{di}=$ inner diameter of cylinder,

$=200 * 10^{5 *}\left(\left(115^{2}+100^{2}\right) /\left(115^{2}+100^{2}\right)\right)$

$=144.031 \mathrm{MPa}$

Also the longitudinal stress is given by:

$\sigma_{\mathrm{L}}=\left(\mathrm{P}_{1} \mathrm{R}_{1}^{2}-\mathrm{P}_{2} \mathrm{R}_{2}^{2}\right) /\left(\mathrm{R}_{1}^{2}-\mathrm{R}_{2}^{2}\right)$

Where $\mathrm{P} 1=$ Internal pressure $\left(200 * 10^{5} \mathrm{pa}\right)$

$P_{2}=$ External pressure (atmospheric pressure $=1.0135$

* $\left.10^{5} \mathrm{pa}\right)$

$\mathrm{R}_{1}=$ Internal radius

$\mathrm{R}_{2}=$ External radius $=\left(\left(200 * 10^{5 *}\left(50 * 10^{-3}\right)^{2}\right)-\left(1.0135 * 10^{5 *}\left(57.5^{*} 10^{-}\right.\right.\right.$

$\left.\left.\left.{ }^{3}\right)^{2}\right)\right) /\left(\left(57.5^{*} 10^{-3}\right)^{2}-\left(50 * 10^{-3}\right)^{2}\right)$

$=61.599 * 10^{6} \mathrm{MPa}$

\section{RESULT AND DISSCUSION:}

A. Low carbon steel:

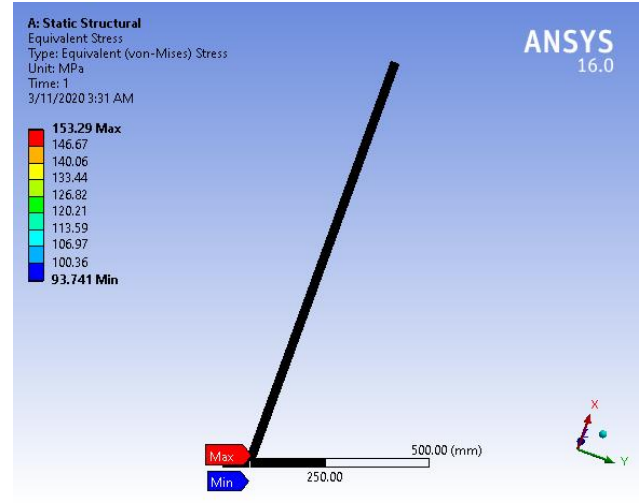

Fig . 1 Stresses in piston rod

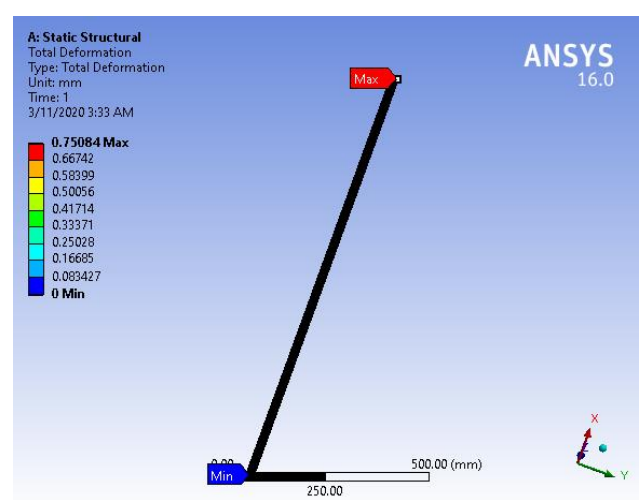

Fig . 2 Deformation in piston rod

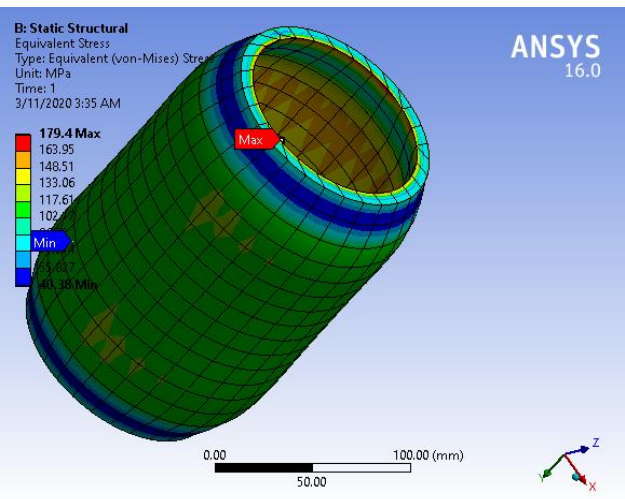

Fig . 3 Stresses in cylinder

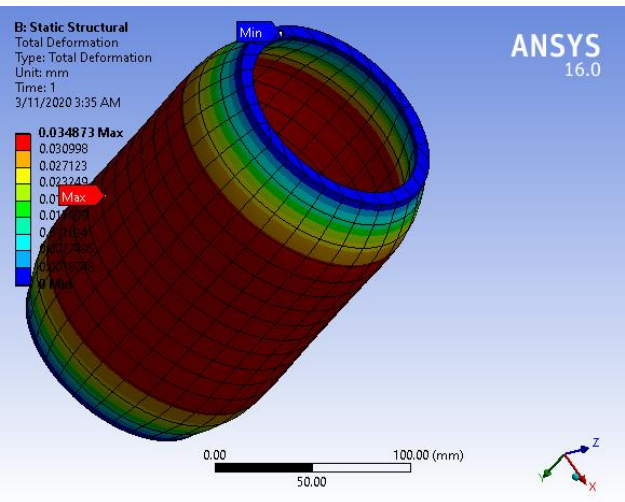

Fig . 4 Deformation in cylinder 


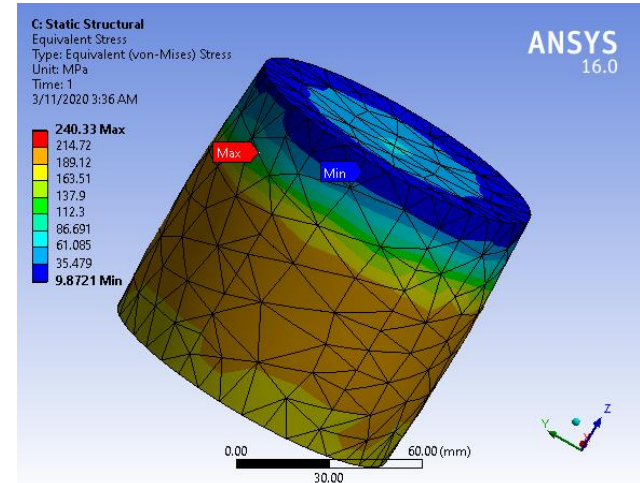

Fig . 5 Stresses in piston

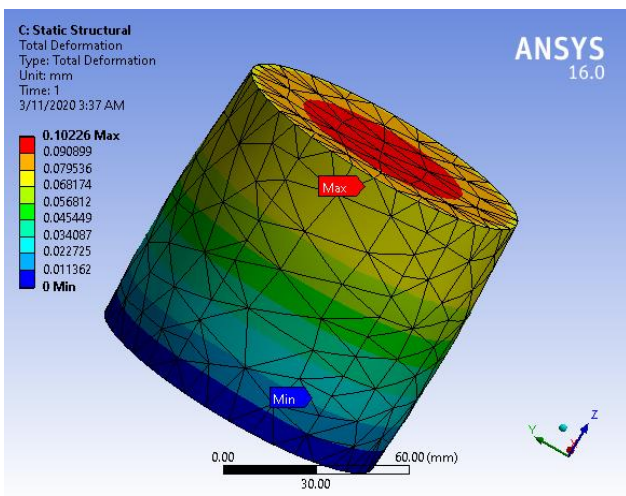

Fig . 6 Deformation in piston

Table 2. Low Carbon Steel

\begin{tabular}{|l|l|l|l|}
\hline & Rod & Cylinder & Piston \\
\hline Stresses (MPa) & 153.29 & 179.4 & 240.33 \\
\hline Total deformation (mm) & 0.75084 & 0.034873 & 0.10226 \\
\hline
\end{tabular}

\section{B. E355 Steel :}

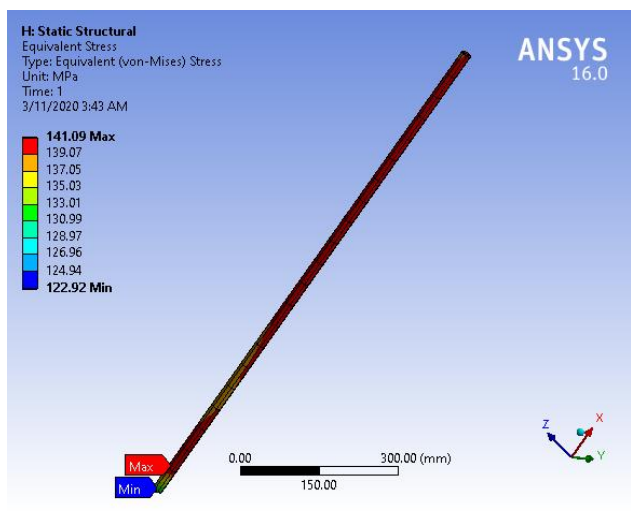

Fig . 7 Stresses in piston rod

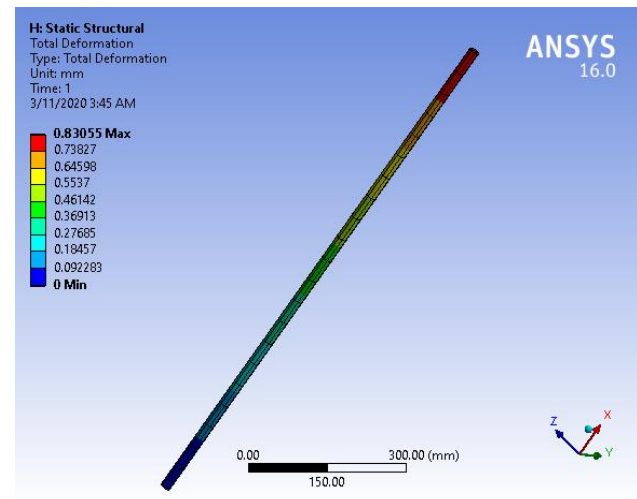

Fig . 8 Deformation in piston rod

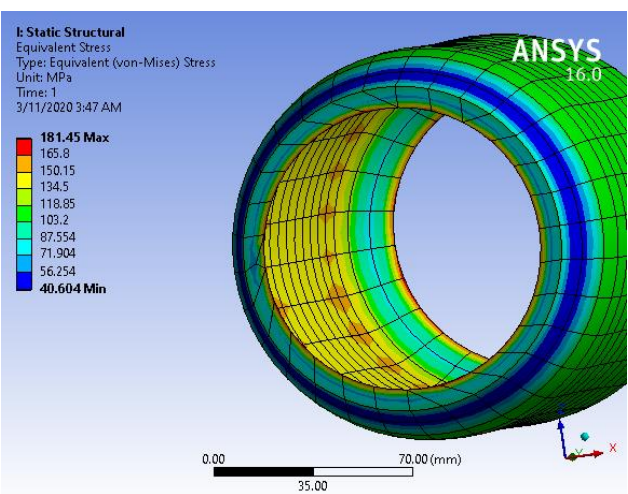

Fig . 9 Stresses in cylinder

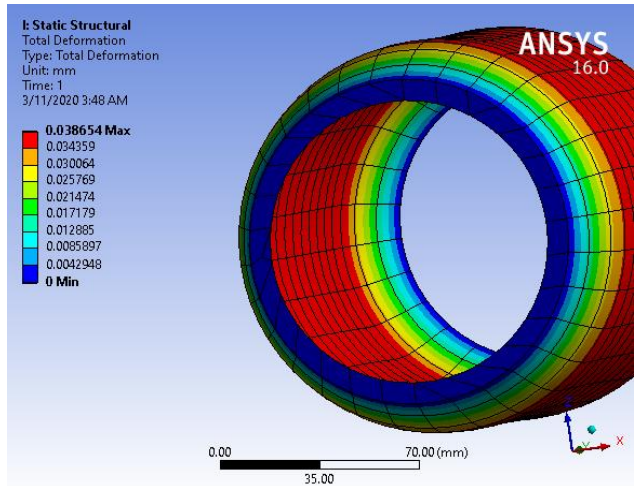

Fig . 10 Deformation in cylinder

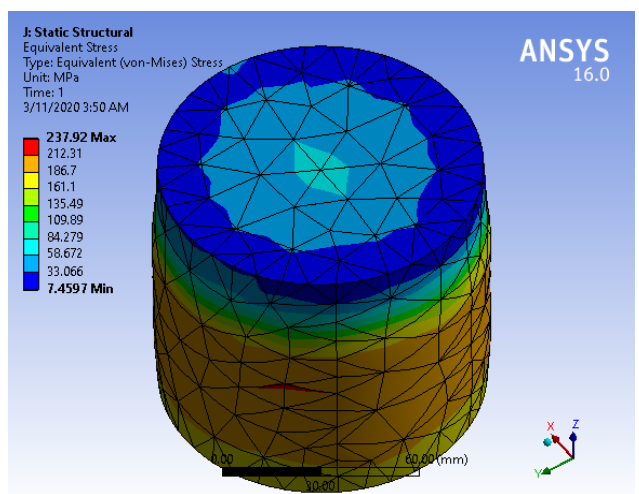

Fig . 11 Stresses in piston 


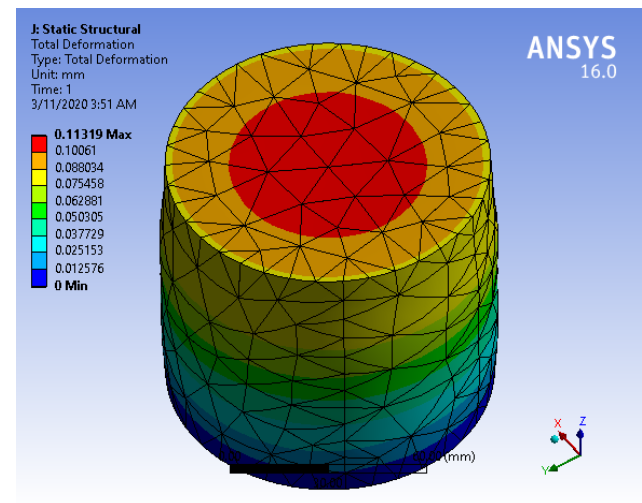

Fig. 12 Deformation in piston

Table 3 . E355 steel

\begin{tabular}{|l|l|l|l|}
\hline & Rod & Cylinder & Piston \\
\hline Stresses (MPa) & 141.09 & 181.45 & 237.92 \\
\hline Total deformation $(\mathrm{mm})$ & 0.83055 & 0.038654 & 0.11319 \\
\hline
\end{tabular}

\section{V.CONCLUSION}

Here, design and analysis of different parts of actuator i.e, piston rod, piston, cylinder is done using CATIA V5 and ANSYS . From the above obtained value, we can conclude that the stresses developed in low carbon steel are more than E355 steel and the total deformation of E355 is more than low carbon steel. Hence from obtained data it is beneficial to use E355 steel.

\section{REFERENCES}

[1] ThankGod E. Boye, Adeyemi, I. Olabisi,Eyere E. Emagbetere ,Design and Finite Element Analysis of Double - Acting, Double - Ends Hydraulic Cylinder for Industrial Automation Application Volume-6, Issue-3, pp-131-138

[2] Willian E. Hurst, Piezo-Hydraulic actuator Design, and Modeling Using Lumped Parameter Approach. M.S Thesis Virginia Polytechnic Institute and State University, 2002

[3] William Durfee, Zongxuan Sun and James Van de Ven, Fluid Power System Dynamics, Center for Compact and Efficient Fluid Power University of Minnesota Minneapolis, USA 2015.

[4] CHEN, Luo, and Ji-zhao LIANG. "Application of complex method in optimal design of hydraulic cylinder supported with flange [J]." Machinery Design \& Manufacture 3, 2010): 038.

[5] Omar F, Jim T, Mohini S. Lightweight and Sustainable Materials for Automotive Applications. CRC Press, 2017.

[6] V.N. Fomenko, The development of protecting systems of hydraulic actuators of mounting mechanisms of traction and special transport vehicles, Ph.D. thesis in Engineering Science, Volgograd, 2000, pp. 16-39.

[7] Ashby F.M and Jones, R.B.H., Engineering Material: An introduction to their properties and application (2nd Edition), Oxford Butter Worth Heinmann, 2002.

[8] Solazzi, L., Design and experimental tests on hydraulic actuator made of composite material, Composite Structures (2019)

[9] Z.Y. Lv et al., A practical approach for evaluating safe fatigue life of hydraulic actuator in helicopter based on a nominal force concept and minimal datasets, Aerosp. Sci. Technol. (2016)

[10] SáowiĚski K, Wuwer W. Buckling resistance of closely spaced bars with Semi-rigid joints under axial compression. In proceeding of 7th European Conference on Steel and Composite Structures. Italy: Naples, September 10 _12, 2014
[11] RavishankarN., Finite Element Analysis of Hydraulic Cylinders.Journal Mech. Des 103(1), 239-243, 1981

[12] Ţălu D.L.Mihai1, Ţălu D.L. Ştefan, A Finite Element Analysis Of Hydraulic Cylinder Of Linear Hydraulic Motor From Horizontal Hydraulic Press - 2 Mn, Journal of Engineering Studies and Research - Volume 16 (2010) No. 4 pp.59-62

[13] A Textbook of Machine design by R. S. Khurmi , Mechanical Engineering Design by Shigley. 